\title{
Phenomenological model of information operation in social networking services
}

\author{
Kateryna Molodetska ${ }^{1}$, Yuriy Tymonin ${ }^{2}$, Oleksandr Markovets ${ }^{3}$, Andrii Melnychyn ${ }^{4}$ \\ ${ }^{1,2}$ Department of Computer Technologies and Systems Modeling, Zhytomyr National Agroecological University, Ukraine \\ ${ }^{3}$ Department of Social Communications and Information Activities, Lviv Polytechnic National University, Ukraine \\ ${ }^{4}$ Theory of Optimal Processes Department, Ivan Franko National University of Lviv, Ukraine
}

\begin{tabular}{l} 
Article Info \\
\hline Article history: \\
Received Jan 8, 2020 \\
Revised Mar 10, 2020 \\
Accepted Mar 24, 2020 \\
\hline
\end{tabular}

\section{Keywords:}

Actors

Content

Information operation Information security of the state Social networking services Threat

\begin{abstract}
In modern conditions, social networking services have become the users' leading channel of communication, which are called actors. Therefore, social networking services are used by intruders to gain benefits in the information space of virtual communities for further influence on political and social processes in the state. In the article the phenomenological model of information operation in social networking services is developed. The model allows to take into account the processes of development of social networking services through the formation of new relationships between actors and the formation of virtual communities. At the same time, behind the model are the processes of degradation of social networking services that are associated with the dissipation of content. The developed model is used for experimental research of real information operation in social networking services. The obtained results will increase the efficiency and effectiveness of counteracting the threats to information security of the state in social networking services by the relevant departments.
\end{abstract}

Copyright $@ 2020$ Institute of Advanced Engineering and Science. All rights reserved.

\section{Corresponding Author:}

Kateryna Molodetska,

Department of Computer Technologies and Systems Modeling,

Zhytomyr National Agroecological University,

Staryy Blvd., 10008, Zhytomyr, Ukraine.

Email: kmolodetska@gmail.com

\section{INTRODUCTION}

The changes that have taken place in the strategic communication system are primarily due to the latest advances in information technology. Currently, social networking services (SNS) cover the largest part of the world market of mass communication [1,2]. Such popularity is associated with the dynamic development of tools for interacting users of SNS - actors, the constant addition of their functional characteristics to new opportunities, increasing the effectiveness of interaction between actors in virtual communities, etc. [3, 4]. The result of such phenomena has been the transformation of SNS into a virtual platform, which ensures the unification of all spheres of social activity and allows the involvement of different types of productive resources - labor, financial, material, etc. At the same time, SNS provides wide opportunities for the expression of will and interests of citizens, and, as a consequence, the formation of civil society. SNS tools allow not only the exchange of content of different types, but also create virtual communities and coordinate the offline citizens' actions for further influence on state processes in real life.

Taking into account the significant influence that SNS is doing in shaping the national information space of each state of the world, they have become the object of threat impact onto the state's information security [4-12]. Due to the content distribution of destructive matter in the information space of SNS, information operations are being carried out, the purpose of which may be to manipulate public opinion to achieve the opposing side of the set goals - incitement of citizens to the protest movement, manifestations of 
hostility on different grounds, overthrow of the constitutional order of the state, etc. Such criminal actions still take place not only in Ukraine, as a result of a hybrid war with the Russian Federation, but also throughout the world [4, 12]. In particular, facts of interference in the US presidential election in 2016 and in the British parliamentary elections in 2017 [13] have been discovered by manipulating the public opinion of the actors in SNS, the use of informational influence on French citizens to incite "yellow waistcoats" in 2018 [14], etc.

Thus, there is an objective contradiction between the need to ensure sustainable development and the security of the world's information space while using SNS by actors on the one hand, and the lack of effective approaches to providing the state's information security in SNS under the conditions of globalization of the information space and cross-border content sharing. The object of the study is the processes of actors' interaction in SNS under the conditions of destructive information influence. Due to the extension of SNS content of destructive matter, the parameters of actors' interaction processes in virtual communities are changing. In this case, the self-organization of actors occurs, as a result of which virtual communities change their structure, are created or decomposed, and the connections between individual actors in SNS weaken or intensify. The subject of the study is the actors' distribution of virtual communities in SNS content of destructive matter during information operations. Existing research on the processes of interaction between actors in SNS is descriptive $[15,16]$ or aimed at solving individual problems related in particular to studying the change in the demand of actors for the content of destructive matter [17], the development of information technology analysis and the identification of information influence [18, 19].

The purpose of the article is to formalize the processes of content distribution of destructive matter by actors in SNS in conducting information operations against state information security. To achieve the set goal, the following subproblems need to be solved: to formalize the processes of growth and dissipation that occur in SNS while conducting information operations by an opposing party; to develop the phenomenological model of information operation in SNS; to study the phenomenological model of information operation in SNS by means of mathematical modeling for studying the influence of individual parameters; to undertake an experimental study of the phenomenological model of the information operation in SNS on the example of real information operation in the information space of virtual communities.

The analysis of recent studies and publications [20,21] has showed that SNS belongs to the class of complex nonlinear dynamic systems. In particular, in some works $[17,22]$ it is proved that such systems are characterized by the following factors: openness to the external in relation to SNS of the information space; disequilibrium due to the heterogeneity of actors' communication processes within the virtual community; dissipativity due to the openness of SNS to the content from other social media; the tendency of actors of virtual communities to self-organization as a result of information influence. Despite the ability of SNS actors' interactions to move into chaotic dynamics, virtual communities turn into uncontrolled objects with unpredictable behavior. In accordance with the situation of the chaos theory, SNS is sensitive to changes in the parameters of the information space of virtual communities as a result of the materializing of SNS threats. At the points of bifurcation, which represents the critical states of the actors' virtual community in SNS, there is uncertainty about the further trajectory of its evolution. In the case of carrying out destructive information influence exactly at the point of bifurcation, SNS moves to the predefined by the opposing party attractor, in which the given state of SNS is realized. Then actors of SNS, as a result of manipulation of public opinion, turn into artificially controlled objects not only in the information space, but also in real life. At the same time, such informational influence and management of actors are not only hidden, but also difficult to detect.

From the work [4] it is known that the main forms of information actions by the opposing party are the information stocks, which are united in information operations and those in turn - in information campaigns. A considerable amount of academic research is devoted to solving the problem of studying the peculiarities of such information operations and their forecasting possibilities. Hryshchyk in [4] proposes a generalized model of information-psychological impact, which can be used in SNS. The analysis of the literature on the direction of the study shows that a monograph [22] presents a series of social procedures' models used to carry out information operations, in particular in SNS. The work [23] is devoted to the development of a mathematical model of information communications in terms of the volume and importance between sources and consumers of information while preparing for a special operation. In [24] a model of information influence and models and methods of counteraction to special cybernetic operations in sociotechnical systems are given. However, the models considered in [4, 18-24] do not take into account the peculiarities of the realization of information operations in SNS, in particular, the carrying out of separate information actions, united by a common purpose, the critical perception by actors of destructive content of directed matter that extends during information operations, changes in the dynamics of interaction processes of actors in SNS and the possibility of further transition of the system to uncontrolled state. Consequently, due to the complex nature of the processes of social communication in SNS, the study of such phenomena requires the development of such mathematical models of information operations in SNS, which will allow to formalize and detect processes of actors' chaotic interaction in advance. 


\section{METHOD}

\subsection{The dynamic features of social networking services}

From the theory of dynamic systems it is known that the evolution of SNS as an open system occurs through the chaos $[20,22]$. At the same time, the contradiction between possible directions of its development as a result of information operations against the state's information security in SNS, the transition to chaotic interaction of actors or the ordering of virtual communities remains a topical issue. The degradation of SNS to a chaotic state is characterized by a high level of entropy of the information space, while the relationships between actors are becoming disordered, and the degree of orderliness of interaction in virtual communities is reduced. On the other hand, the evolutionary development of SNS is associated with the cooperative interaction of actors and synchronization of the processes of their social communication, resulting in the level of information entropy decreases and as a result of self-organization, new stable structures - virtual community of actors - are formed. These two areas of the development of SNS are consistent with each other by global evolutionism and are mutually determined [25]. Therefore, we formulate a series of limitations to develop a model of information operations in SNS against the state's information security.

a) Limitation 1. The model of information operations in SNS should take into account the processes of development and degradation of actors' virtual communities due to the impact of destructive content's matter.

b) Limitations 2. The main variable of the information operation model in SNS should be information of different types - content that is distributed to SNS and consumed directly by actors as a result of their interaction with other actors and virtual communities.

In addition, we will use the results of studies [26], which formalize the behavior of living systems in the transition to chaotic dynamics. Based on the above restrictions, we will develop a phenomenological model of information operation in SNS, which reflects the interconnection of all components in the realization of the state's information security threats.

\subsection{Development of the phenomenological model of information operation}

The normal functioning of SNS is connected with unlimited distribution of content in their information space. Due to this, the SNS develops consequently by the involvement of new actors interested in the use of unique content on various topics. In the SNS, the structure of the links between actors is complicated - new and weakening ones are formed, associations are merged into virtual communities of actors with relevant worldviews, etc. The increase in the amount of content in SNS leads to a decrease in the level of entropy in the information space of virtual communities. In the context of conducting an information operation in SNS, such content contains destructive information influence on actors, and is based on an effective narrative, the purpose of which is to form a given public opinion on a number of specific issues. Such processes are described by the differential equation of form growth

$$
y^{\prime}(t)=\alpha y(t)
$$

where $y(t)$ - the number of content publications of a given matter, spread during conducting the information operations; $\alpha$-coefficient of number growth of publications of the content in the information space of SNS during the conduct of the information operation.

For SNS, the processes of content dissipation (scattering), which are a complex phenomenon in its nature, are inherent. They are connected with the influence which performs the widen content of directed matter during information operations. Under the action of special triggers in actors it is provoked by the appearance of a given emotional state, behavioral reactions, etc. At the same time, such content from SNS spreads to other media and is publicly debated by society at various sites to influence the mass consciousness of citizens. Due to the processes of content dissipation in SNS, the level of the information space's entropy of virtual communities increases, and is expedient to describe by differential equations of the second order

$$
\beta_{2} y^{\prime \prime}(t)+\beta_{1} y^{\prime}(t)+\beta_{0} y(t)=\gamma
$$

where $\gamma$ is the indicator of the dynamics of content publications in SNS, which determines the proportion of virtual content communities scattered in the information space; $\beta_{2}, \beta_{1}, \beta_{0}$ - parameters, determined by the features of SNS information space.

From the theory of complex dynamical systems, it is known that the processes of increasing content's volume in SNS and its dissipation are interrelated. Therefore, it is expedient to formalize the connection between the phenomena considered in the form of the following equation 


$$
\varepsilon=\alpha-\gamma
$$

where $\varepsilon$ - the indicator of the dynamics of SNS content, which widens while conducting an information transaction.

In such a way, the substitution of expression (3) in the differential (1) will allow to take into account the processes of increasing the number of publications of the content of the directed matter in SNS and their dissipation in the information space

$$
y^{\prime}(t)=\varepsilon y(t)
$$

In turn, substitution in the differential (4) of expressions (1)-(3) transforms it into a differential equation of the second order, which is a phenomenological model of information operation in SNS.

$$
\beta_{2} y(t) y^{\prime \prime}(t)+\left(1+\beta_{1} y(t)\right) y^{\prime}(t)+\left(\beta_{0} y(t)-\alpha\right) y(t)=0
$$

For model (5) the physical meaning of the parameters $\beta_{2}, \beta_{1}, \beta_{0}$ requires its refinement. So, it is connected with the size of the capacity of SNS information space and determines the limit value of content publications' volume during the information operation. It limits the processes of increasing the amount of destructive content of the directed matter in SNS. The parameter is determined by the level of actors' critical thinking of virtual communities in SNS and characterizes the reasonable rejection of the distributed narrative to the target audience. The coefficient reflects the level of actors' sensitivity to the content of destructive matter in SNS, the ability to its unconditional acceptance of faith as valid information.

\subsection{Qualitative characteristics of the information operation}

It should be noted that the differential equation (5) in general is analogous to the differential equation of physical systems of the second order, which behavior is described by oscillatory processes [27]. Therefore, for further study of the laws of conducting information operations in SNS, we introduce

\begin{tabular}{|c|c|c|}
\hline $\begin{array}{c}\text { Mathematical } \\
\text { expression }\end{array}$ & Theory of dynamic systems & Model building of information operations in SNS \\
\hline$\omega_{0}=\frac{1}{\sqrt{\frac{\beta_{2}}{\beta_{0}}}}$ & $\begin{array}{l}\text { Resonance frequency is the frequency at which the } \\
\text { amplitude of stationary vibrations sharply } \\
\text { increases with the coincidence of the frequency of } \\
\text { external influences with values characteristic of } \\
\text { this system. }\end{array}$ & $\begin{array}{l}\text { Shows the frequency of information campaigns, in } \\
\text { which the number of content's publications of directed } \\
\text { matter in SNS dramatically increases due to its further } \\
\text { dissemination by actors of virtual communities. }\end{array}$ \\
\hline$\delta=\frac{\beta_{1}}{2 \beta_{2}}$ & $\begin{array}{l}\text { Decremental attenuation - the rate of amplitude's } \\
\text { reduction of harmonic oscillations in time. }\end{array}$ & $\begin{array}{l}\text { Describes the rate of dissipation of the contents' } \\
\text { directed matter in SNS because of its influence on the } \\
\text { actors. }\end{array}$ \\
\hline$\rho=\sqrt{ }$ & $\begin{array}{l}\text { Characteristic resistance is a quantitative } \\
\text { measurement of the energy accumulated by } \\
\text { reactive elements. }\end{array}$ & $\begin{array}{l}\text { The part of distributed during the content promotions } \\
\text { that influenced decision-making processes by actors. }\end{array}$ \\
\hline$Q=\frac{\sqrt{\beta_{2} \beta_{0}}}{\beta_{1}}$ & $\begin{array}{l}\text { Q-factor - the relation between energy store in the } \\
\text { circuit and energy losses during one period of } \\
\text { fluctuations. }\end{array}$ & $\begin{array}{l}\text { The relation between content in SNS, which has been } \\
\text { distributed during the information campaign and the } \\
\text { content, which by no means influences the actors. }\end{array}$ \\
\hline
\end{tabular}
the characteristics as shown in Table 1 that are used in the theory of dynamical systems.

Table 1. Correlating characteristics of dynamic systems and information operation in SNS

The usage of the analyzed in Table 1 characteristics of SNS information operation will allow to perform a qualitative assessment of the effectiveness of its realization in the information space of virtual communities.

\section{RESULTS AND DISCUSSION}

\subsection{Simulation experiment}

To study the suggested phenomenological model of information operation in SNS the mathematical modeling is carried out using means of the MathCad application package. In addition, the phase plane method is used to study the dynamics of the content in the information space of virtual communities in SNS. Let the parameters of the model (5) acquire the following values $\beta_{0}=0.01, \beta_{1}=0.001$ and $\beta_{2}=0.8$. 
We shall investigate the influence of the growth parameter of the publications' number in the information space of SNS with $\alpha_{1}=0.5, \alpha_{2}=0.3, \alpha_{3}=0.1$. In this case, the amount of content in SNS varies as shown in Figure 1.

Thus, the considered growth parameter of the publications' number $\alpha$ in SNS model (5) affects their total amount in the information space and determines the occurrence of transient processes in the virtual communities associated with the response to such content. Small values of the parameter contribute to the guaranteed unchanged level of actors' publication in SNS information space for a given topic. For high values of the parameter, processes for distributing content of destructive matter during an information operation in SNS are converted into a vibrational process.

We simulate the effect of changing the parameter of the information space capacity of SNS with the fixed values of other parameters of the differential (5), in particular, $\alpha=0.5, \beta_{1}=0.001$ and $\beta_{2}=0.8$. It acquires values of $0.01 ; 0.02$ and 0.05 , and the results of simulation are given in Figure 2 .

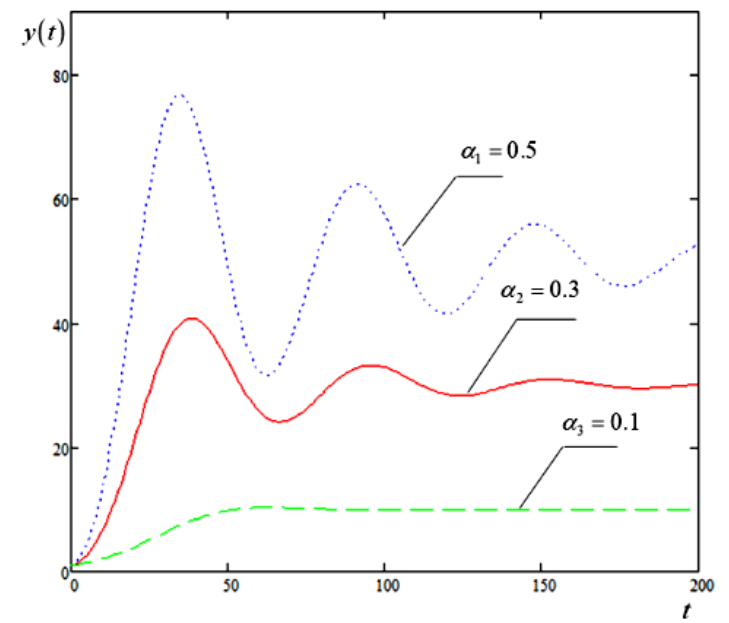

Figure 1. The content dynamics in SNS at different parameter $\alpha$ values

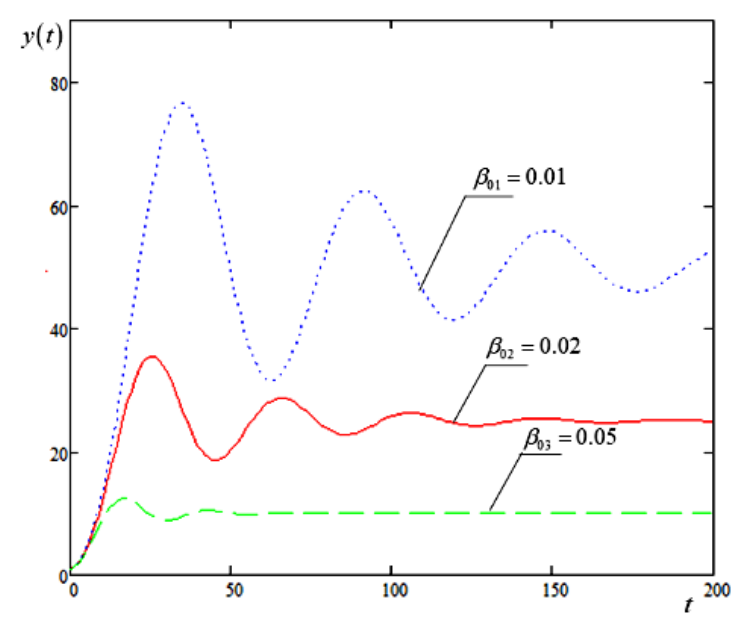

Figure 2. The change in number of SNS content publications at different values of the parameter $\beta_{0}$

The Figure 2 shows that the increase in the size of the capacity of state's information security information space $\beta_{0}$ leads to a decrease in the number of content publications of destructive matter. The consequence of reducing the parameter value $\beta_{0}$ is to increase the number of such publications as a vibrational process.

Let us consider the effect on the content of the destructive matter in SNS parameter $\beta_{1}$, which determines the level of critical thinking of virtual community actors, with fixed values of other parameters of the model (5), $\alpha=0.5, \beta_{0}=0.01$ and $\beta_{2}=0.8$. The simulation results are shown in Figure 3 .

The $\beta_{1}$ model parameter (5) specifies the frequency and amplitude of the oscillatory process, which describes in dynamics the changes of the publications' content number of destructive matter in SNS while conducting an information transaction. Increasing the level of actors' critical thinking in SNS $\beta_{1}$, respectively, leads to a decrease in the amplitude and frequency of such oscillatory process.

We investigate the influence of a parameter $\beta_{2}$ that characterizes the level of actors' sensitivity to the content of destructive matter in SNS, the course of an information operation in the information space of virtual communities (Figure 4). At the same time, the rest of the parameters of the phenomenological model (5) acquire the following meanings $\alpha=0.5, \beta_{0}=0.01$ and $\beta_{1}=0.001$, and $\beta_{2}=0.8 ; 0.5 ; 0.2$. The Figure 4 shows that the increase in the level of actors' sensitivity to the content of destructive matter leads to an increase in the number of its publications in the information space of SNS. The consequence of decreasing this indicator is to reduce the duration of the transition process of the actors' interaction in SNS, which arises as a result of the reaction to the content that extends during the information transaction. 


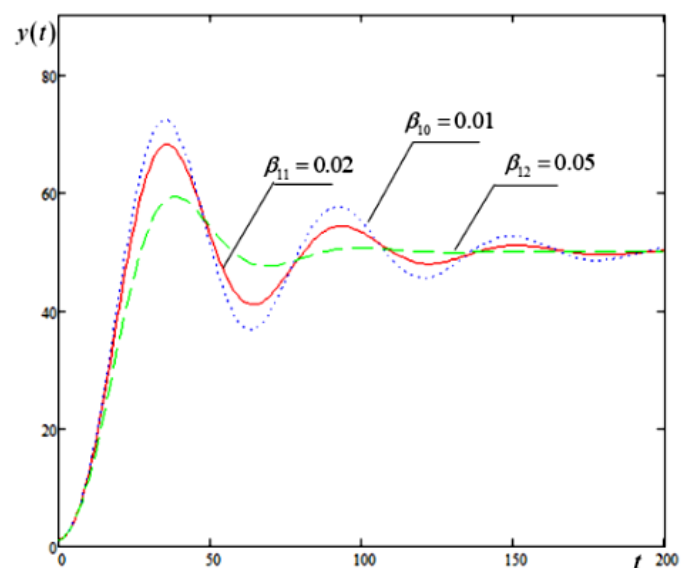

Figure 3. The parameter's $\beta_{1}$ influence on the publications' number in SNS

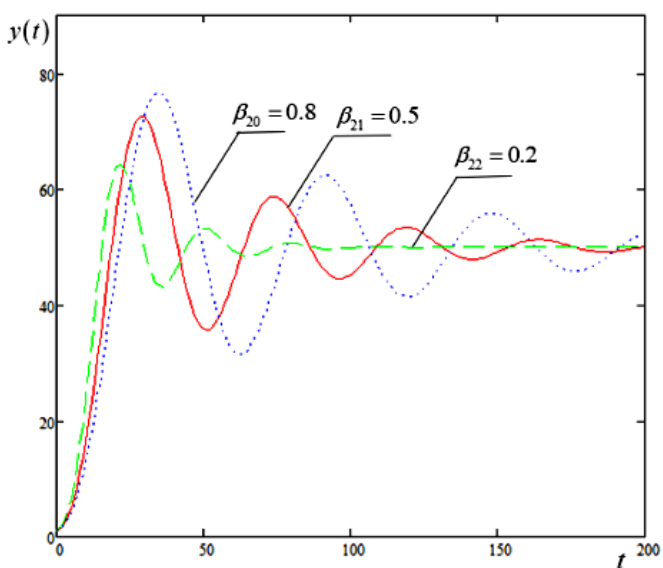

Figure 4. The parameter's $\beta_{2}$ influence on the publications' number in SNS

\subsection{Model research on an example of a real information operation}

An experimental study of the developed phenomenological model has been also carried out on the example of an information operation that has taken place in the information space of Ukraine. On December 15, 2018, a local unification council has been established on which the Orthodox Church of Ukraine has been formed, and already on January 6, 2019, Tomos has received its autocephaly. Recently, the Russian Federation has used the religious question as one of the effective tools for spreading geopolitical influence on Ukraine under conditions of hybridization war [28]. Therefore, the whole process of the Orthodox Church's formation of Ukraine has been accompanied by information actions that have been agreed upon in time and purpose. The opposing party has widened content about the inter-confessional dissent in Ukraine. The considered information drive has been used to study the developed model (5) of the information operation in SNS. For this purpose, the content of the social network GooglePlus has been investigated by means of the service Popsters. The total number of publications, comments, likes and reposts for content relevant to the semantic core in russian <dissent of the Orthodox Church> with targeting in the territory of Ukraine from December 21, 2017 to January 22, 2019 are specified. The analysis results are shown in Figure 5-7.

The records in Figure 5-7 confirm that the information campaign aimed at spreading a narrative about the emergence of a dissent on an interconfessional basis followed by the escalation of the conflict has been conducted by the opposing side in the information space of SNS. The surges in the number of content publications on the given topic and the activation of the actors' reaction on them coincide in time with the preparatory stages prior to the receipt of Tomas, in particular the visit of the Ukrainian President to Istanbul on April 9, 2018 to meet the Ecumenical Patriarch Bartholomew and with the members of the Holy and Sacred Synod; On October 9-11, 2018, the Synod of the Constantinople Orthodox Church, which has confirmed the decision to provide autocephaly and others.

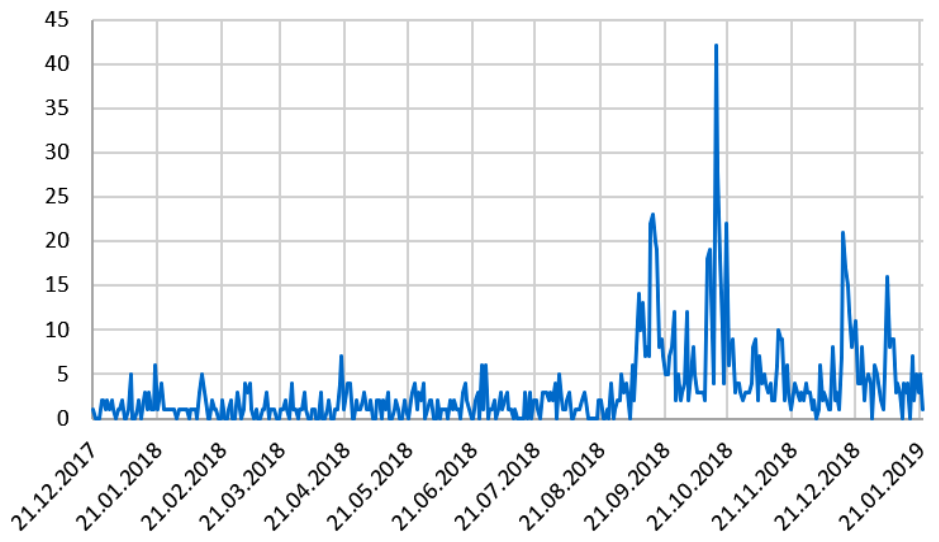

Figure 5. Dynamics of publication of the investigated content 


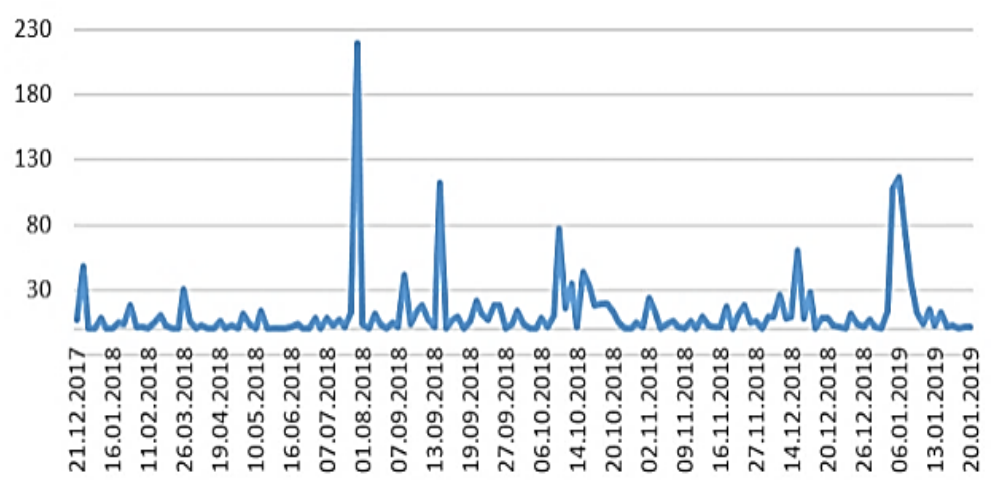

Figure 6. Dynamics of comments to relevant content

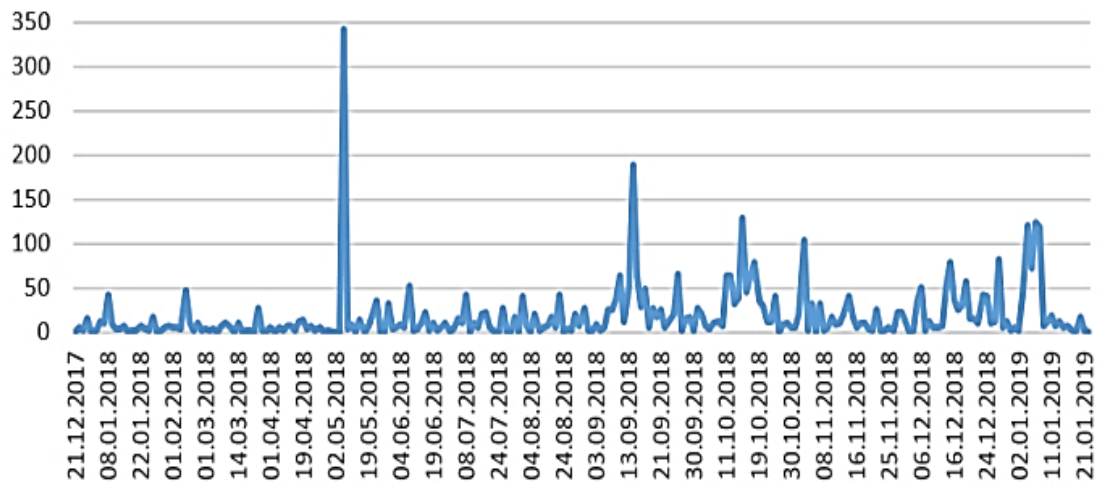

Figure 7. Dynamics of "likes" to relevant content

To confirm the adequacy of the developed phenomenological model of the information operation in SNS (5), we will perform its parametric identification using experimental data. At the same time, we restrict ourselves to the data for the period from September 11, 2018 to October 11, 2018, and the model parameters acquire the following values: the coefficient of the number growth of content publications in the information space of SNS during the information operation $\alpha=1.6$; capacity of SNS information space $\beta_{0}=0.09$; level of critical thinking of virtual community actors in SNS $\beta_{1}=0.005$; the level of actors' sensitivity to the content of destructive matter $\beta_{2}=0.23$. In Figure 8 a comparison of the experimental series of data $u(t)$ and data $y_{\exp }(t)$ obtained on the basis of the model (5) have been performed.

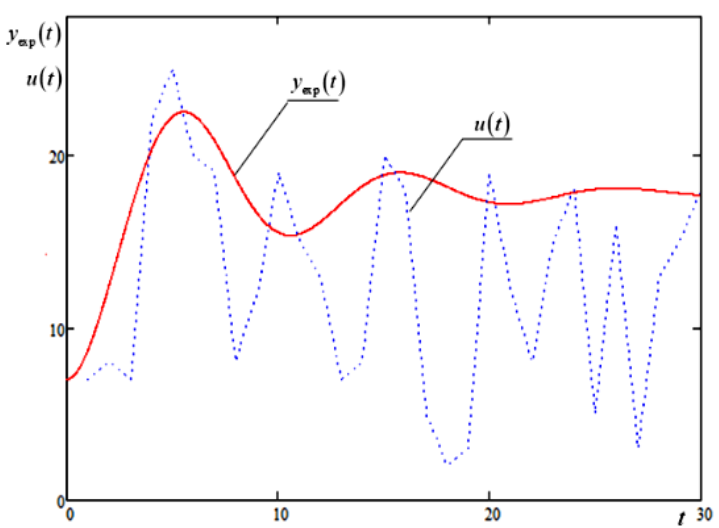

Figure 8. Comparison of experimental data and obtained using the developed model 


\subsection{Performance calculation of the information operation}

In addition, the calculation of the qualitative characteristics of the information operation, given in the Table 1 is carried out. For the investigated information operation in state's information security, they acquire the following values: resonant frequency $\omega_{0}=0.63$ of days ${ }^{-1}$; attenuation factor $\delta=0.01$ days $^{-1}$; characteristic resistance $\rho=0.14$; Q-factor $Q=28.77$. The use of such data will allow to develop adequate measures for information counteraction to threats to the state of information security in SNS. In particular, the magnitude of the resonant frequency indicates the inadmissible frequency of intrusion by some of the information actions in SNS to prevent the emergence of actors' emotional resonance and the transition of virtual communities to the chaotic dynamics of interaction and uncontrolled state. The attenuation factor shows the speed of the destructive impact of the content, which extends during the information operation in SNS, on the actors and determines the necessary reaction rate of the relevant departments to opposing the threats to information security. The characteristic resistance points to the content of the destructive matter, which has already negatively affected the decision-making processes of actors in real life. The Qfactor determines the relationship between the content in SNS, which has been distributed during the information campaign and the content, which in no way has influenced the actors.

\section{CONCLUSION}

For the first time, a phenomenological model of informational operation in SNS has been developed. It allows us to accommodate the processes of progress and regress of virtual communities in the information space under the influence of destructive content. In the field of information security, we are the first to introduce a qualitative assessment of informational operations in the SNS information space using the theory of dynamic systems. It's necessary to underline that the usage of the developed model in order to create and improve the components of the state information security system enhances the effectiveness and efficiency of measures to counteract threats in the SNS. We have also conducted the research of the influence of the parameters of the phenomenological model of information operation in SNS on the dissemination of destructive content in the information space of virtual communities by the actors. An experimental study of the developed model was carried out using the data from a real information operation in the SNS related to the creation of the Orthodox Church of Ukraine which aimed at the inter-confessional division of society inside the country. The adequacy of the developed model to formalize the dissemination of the content of destructive content in SNS is clearly stated and proved. The sphere of further research is meant to investigate the functional dependence of the parameters of the developed phenomenological model on the features of the SNS information space.

\section{REFERENCES}

[1] Shailendra R., et al., "Social network security: Issues, challenges, threats, and solutions," Information sciences, vol. 421, pp. 43-69, 2017.

[2] S. E. Chang, et al., "User trust in social networking services: A comparison of Facebook and LinkedIn," Computers in Human Behavior, vol. 69, pp. 207-217, 2017.

[3] A. Peleshchyshyn, et al., "Identifying specific roles of users of social networks and their influence methods," in Proc. of 2018 IEEE 13th International Scientific and Technical Conference on Computer Sciences and Information Technologies, CSIT 2018, pp. 39-42, 2018.

[4] R. V. Hryshchuk and Y. G. Danik, "Foundations of cyber security,” ZhNAEU, Zhytomyr, p. 636, 2016.

[5] I. Korobiichuk, et al., "Determination and evaluation of negative informational and psychological influence on the military personnel based on the quantitative measure," in Proc. 1st International Workshop Control, Optimization and Analytical Processing of Social Networks, vol. 2392, pp. 66-78, 2019.

[6] J. Straub, "Mutual assured destruction in information, influence and cyber warfare: Comparing, contrasting and combining relevant scenarios," Technology in Society, vol. 59, p. 101177, 2019.

[7] Virginia I. and O. Turel, "Manipulating user resistance to large-scale information systems through influence tactics," Information \& Management, vol. 57, no. 3, p. 103178, 2020.

[8] Monther A. and A. Alwahedi, "Detecting fake news in social media networks," Procedia Computer Science, vol. 141, pp. 215-222, 2018.

[9] K. Molodetska, et al., "The conceptual model of information confrontation of virtual communities in social networking services," International Journal of Electrical and Computer Engineering, vol. 10, no. 1, pp. 1043-1052, 2020.

[10] O. V. Trach and A. Peleshchyshyn, "Functional-network model of tasks performance of the virtual communities life cycle directions," in Proceedings of the 11th Intern. Scientific and Technical Conference, CSIT 2016, pp. 108-110, 2016.

[11] R. Hryshchuk, et al., "Method of improving the information security of virtual communities in social networking services," in Proceedings of 1st International Workshop Control, Optimization and Analytical Processing of Social Networks, vol. 2392, pp. 23-41, 2019.

Phenomenological model of information operation in social networking services (Kateryna Molodetska) 
[12] V. V. Lysenko and K. C. Desouza, "Moldova's internet revolution: Analyzing the role of technologies in various phases of the confrontation," Technological forecasting and social change, vol. 79, no. 2, pp. 341-361, 2012.

[13] The Sunday Times, "Exposed: Russian Twitter Bots Tried to Swing General Election for Jeremy Corbyn," 2018. Available: https://cutt.ly/OryLgdB.

[14] C. Matlack and R. Williams, "France to Probe Possible Russian Influence on Yellow Vest Riots," 2018. Available: https://cutt.ly/cryLfwb.

[15] T. Bilushchak, et al., "Development of method of search and identification of historical information in the social environment of the internet," in Proc. of the 12th International Scientific and Technical Conference on Computer Sciences and Information Technologies, CSIT 2017, pp. 196-199, 2017.

[16] I. Kayes and A. Iamnitchi, "Privacy and security in online social networks: A survey," Online Social Networks and Media, vol. 3-4, pp. 1-21, 2017.

[17] R. Hryshchuk and K. Molodetska, "Synergetic Control of Social Networking Services Actors' Interactions," in Recent Advances in Systems, Control And Information Technology: Proceedings of the International Conference SCIT 2016, vol. 543, pp. 34-42, 2017.

[18] M. Weskida and R. Michalski, "Finding Influentials in Social Networks using Evolutionary Algorithm," Journal of Computational Science, vol. 31, pp. 77-85, 2018.

[19] J. Wan, et al., "Information propagation model based on hybrid social factors of opportunity, trust and motivation," Neurocomputing, vol. 333, pp. 169-184, 2019.

[20] S. Wasserman and K. Faust, "Social Network Analysis: Methods and Applications," Cambridge university press, Cambridge, England, 1994.

[21] J. M. Epstein, “Generative Social Science: Studies in Agent-Based Computational Modeling,” Princeton University Press, Princeton, USA, 2006.

[22] V. P. Horbulin, et al., "Information operations and safety of society: threats, opposition, modeling," Intertechnology, Kyiv, 2009.

[23] M. H. Pozveh, et al., "Assessing information diffusion models for influence maximization in signed social networks," Expert Systems with Applications, vol. 119, pp. 476-490, 2019.

[24] D. Dang-Pham, et al., "Investigation into the formation of information security influence: Network analysis of an emerging organisation," Computers \& Security, vol. 70, pp. 111-123, 2017.

[25] I. V. Il'in, et al., "Global evolutionism: Ideas, problems, hypotheses," Izd-vo Moskovskogo universiteta, p. 616, 2012.

[26] Y. Tymonin and Y. Brodskyi, "Hybrid phenomenological model of dynamic chaos," in Transformation of ukrainian society and its elite in the context of civilization development of Europe, pp. 116-120, 2018.

[27] S. W. Rohrer and R. A. Director, "Introduction to System Theory," McGraw-Hill, p. 300, 1972.

[28] T. Kuzio, "Why Independence for Ukraine's Orthodox Church Is an Earthquake for Putin," 2018. Available: https://cutt.ly/JryLdro.

\section{BIOGRAPHIES OF AUTHORS}
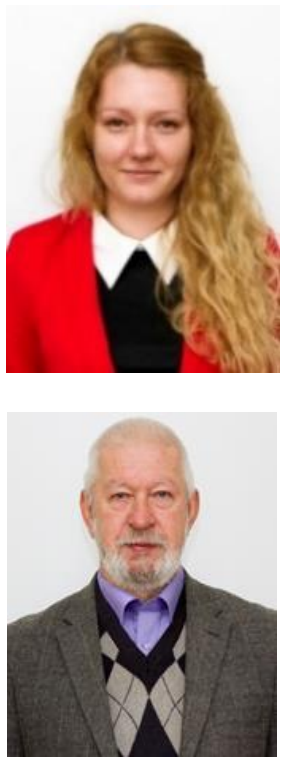

Kateryna Molodetska (1985), Doctor of Technical Sciences, Associate Professor, Professor of Computer Technology and Modeling Systems Department in Zhytomyr National Agroecological University. Graduated with honors from Zhytomyr Military Institute named after S. P. Korolyov. Studied at the postgraduate school of the Department of Hybrid Control and Modeling Systems in the Energy Institute of the Problems of Modeling in the Power Engineering named after G. E. Pukhov in the National Academy of Sciences of Ukraine. The sphere of scientific interests is connected with mathematical modeling and information security.

Yurii Tymonin (1945), Candidate of Technical Sciences, Associate Professor, Assistant Professor of Computer Technology and Modeling Systems Department in Zhytomyr National Agroecological University. Graduated from the Leningrad Electrotechnical Institute. Awarded the Silver Medal on the Exhibition of Achievements of the National Economy of the USSR and the Sign "Inventor of the USSR". The sphere of scientific interests is connected with simulation of processes and systems of various physical nature. 


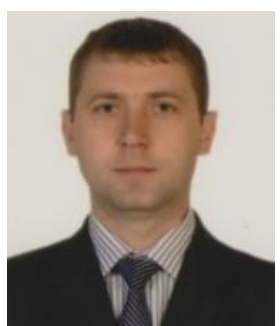

Oleksandr Markovets (1979), Candidate of Technical Sciences, Associate Professor of the Department of Social Communications and Information Activities at the Institute of Humanities and Social Sciences at Lviv Polytechnic National University. In 2001 he graduated from the Institute of Computer Sciences and Information Technologies Lviv Polytechnic National University in the specialty "Intellectual Decision Making Systems" and received a Master's Degree in Computer Science. The sphere of scientific interests is connected with processing of citizens' requests and electronic document flow.

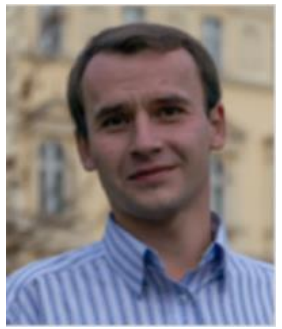

Andrii Melnychyn (1981), Candidate of Technical Sciences, Associate Professor, Associate Professor of Theory of Optimal Processes Department of Ivan Franko National University of Lviv. Graduated from Ivan Franko National University of Lviv, Faculty of Applied Mathematics and Informatics majoring in "Social Informatics". Research interests - modeling and optimization of access to information in databases. 